\title{
Allogeneic and Autogenous Bone Grafts Are Affected by Historical Donor Environmental Exposure
}

\author{
Caleb Behrend MD $@$, Jonathon Carmouche MD, Paul W. Millhouse MD, \\ Lauren Ritter MPH, Joseph Moskal MD, Paul Rubery MD, \\ Edward Puzas PhD
}

Published online: 28 October 2015

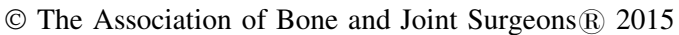

\begin{abstract}
Background Bone graft materials are routinely evaluated for infectious agents; however, data regarding contamination of bone graft from environmental exposure of the donors to osteotoxic substances such as lead are not routinely available. In animal models, stored lead in bone has been shown to impair fracture healing and osteocyte
\end{abstract}

Each author certifies that he or she, or a member of his or her immediate family, has no funding or commercial associations (eg, consultancies, stock ownership, equity interest, patent/licensing arrangements, etc) that might pose a conflict of interest in connection with the submitted article.

All ICMJE Conflict of Interest Forms for authors and Clinical Orthopaedics and Related Research ${ }^{(\mathbb{R}}$ editors and board members are on file with the publication and can be viewed on request. Clinical Orthopaedics and Related Research ${ }^{\circledR}$ neither advocates nor endorses the use of any treatment, drug, or device. Readers are encouraged to always seek additional information, including FDAapproval status, of any drug or device prior to clinical use. This work was performed at Virginia Tech Carilion, School of Medicine and Research Institute, Carilion Clinic, Roanoke, VA, USA; and Strong Memorial Hospital, The University of Rochester, Rochester, NY, USA.

C. Behrend ( $₫)$, J. Carmouche, J. Moskal

Department of Orthopedic Surgery, Carilion Clinic, Virginia

Tech Carilion School of Medicine and Research Institute,

3 Riverside Circle, Roanoke, VA 24016, USA

e-mail: behrend@ucla.edu

P. W. Millhouse

Department of Orthopaedic Research, Rothman Institute,

Philadelphia, PA, USA

L. Ritter

Columbia University, New York, NY, USA

P. Rubery, E. Puzas

School of Medicine and Research Institute, University of Rochester, Rochester, NY, USA function. In clinical studies, lead is linked to skeletal disease at relatively low concentrations. Presumably the levels of lead in allografts mirror the level of lead in bone in the population; however, the degree to which processing might decrease this and the frequency with which potentially osteotoxic levels appear in bone grafts have not been studied.

Questions/purposes (1) Does processing of donor bone for allografts result in lower concentrations of lead in commercial allograft when compared with autologous bone graft; and (2) what proportion of bone grafts contain potentially osteotoxic levels of lead from $>2.0$ to $20.0 \mu \mathrm{g} / \mathrm{g}$ corresponding to environmental exposure?

Methods Allograft from commercial sources and autologous bone graft materials were examined for lead content using ICP- atomic absorption spectrophotometric analysis. We analyzed bone graft specimens from 42 donors, including 26 corticocancellous tibial specimens from commercially available bone graft materials and 16 autograft corticocancellous tibial specimens. Lead levels were determined for the cortical $(n=42)$ and cancellous $(n=42)$ portions of each specimen. For quality control, all instruments, plastic and glassware, were regularly tested for lead contamination by atomic absorption spectrophotometry throughout the experiments. In addition, spectrophotometer calibration was verified using Standard Reference Material 1486 bone meal (NIST, Gaithersburg, MD, USA). Descriptive statistical analysis was performed using SPSS 20 (SPSS Inc, Chicago, IL, USA). Using these techniques, a lead level $>2 \mu \mathrm{g} / \mathrm{g}$ to $20 \mu \mathrm{g} / \mathrm{g}$ corresponds to some degree of environmental exposure to lead.

Results With the numbers available in the present study, there were no differences in mean lead level between commercial bone graft materials and autogenous bone graft, $2.1 \mu \mathrm{g} / \mathrm{g}$ (95\% confidence interval [CI], 1.6-3.3 $\mu \mathrm{g} / \mathrm{g}$ ) 
versus $2.0 \mu \mathrm{g} / \mathrm{g}(95 \% \mathrm{CI}, 1.0-4.5 \mu \mathrm{g} / \mathrm{g} ; \mathrm{p}=0.86)$. The range for all tested samples varied from $<0.1$ to $5.0 \mu \mathrm{g} / \mathrm{g}$. Likewise, there were no differences in mean lead level between cortical bone grafts, which contained $2.2 \mu \mathrm{g} / \mathrm{g}$ (95\% CI, 1.5-3.7 $\mu \mathrm{g} / \mathrm{g}$ ), and cancellous grafts, which contained $1.9 \mu \mathrm{g} / \mathrm{g}(95 \% \mathrm{CI}, 1.2-3.4 \mu \mathrm{g} / \mathrm{g} ; \mathrm{p}=0.58)$. Thirty-eight percent (16 of 42) of the specimens had levels between $2.0 \mu \mathrm{g} / \mathrm{g}$ and $20 \mu \mathrm{g} / \mathrm{g}$ within a range expected for individuals with known environmental exposure to lead. Conclusions This study demonstrates that lead is present in up to one-third of tibial allograft and autograft bone specimens at potentially osteotoxic levels regardless of the source or screening. Further research is needed to delineate the relationship with nonunion or pseudoarthrosis after procedures in which allograft is used. In addition, further study would examine concentrations of lead and other environmental contaminants in other graft types.

Clinical Relevance Comparable levels of lead exposure have been associated with toxic effects on skeletal tissue. Further study of bone graft used in fusion procedures and other procedures is necessary to define the magnitude of osteotoxic effects in the setting of fracture care or fusion procedures.

\section{Introduction}

Bone graft products are used in more than 500,000 procedures performed annually in the United States including treatment of fractures and fusions [1, 7, 9]. The role of quality or composition of graft materials in failures of treatments by nonunion is not clear. The mechanism by which graft material stimulates the formation of new bone is through resorption of the graft by host osteoclasts and/or macrophages with the subsequent release of proanabolic growth factors from the graft [20]. Other substances that are present in the bone graft are also released during the resorptive process such as lead or cadmium. Environmental contamination of graft bone such as lead is present within the some graft materials in trace quantities. The possibility that the subset of grafts with higher concentrations of such substances could be among the factors contributing to the success or failure of fusions or fracture nonunions is of clinical interest [7].

Bone allograft materials are routinely evaluated for infectious agents; however, data regarding contamination of bone graft from environmental exposure of the donors to osteotoxic substances are not routinely available. The lead content of bone from humans exposed to environmental sources ranges from 2 to $20 \mathrm{ppm}$ [20]. In animal models and clinical studies, lead has specifically been shown to be a source of adverse cellular effects resulting in skeletal disease $[3,5,20,22]$. The mechanism for the skeletal effects is thought to be related to release of lead from the bone compartment with subsequent molecular consequences on key signaling pathways in the osteoblasts [6]. Commercially available graft materials and substitutes are subjected to quality measures based on FDA regulations. Currently there are little available data on known osteotoxic substances present in these materials [9]. Graft material donors undergo screening as well as serologic and microbiologic testing according to current standards established by the American Association of Tissue Banks for bone bank allografts [1]. A detailed inquiry into donor medical history is performed, which includes the donor's history of exposure to toxic substances that may affect tissues. Blood samples are also taken from the donor to test for a wide variety of transmissible diseases [9]. Screening for exposure to toxic substances, including metals such as lead, is only suggested by available information from the donor's medical and social history. No routine objective analytical measurement of donor exposure to osteotoxic substances is included in available standard published testing protocols for bone. Presumably the levels of lead in allografts mirrors the level of lead in bone in the population; however, the degree to which processing might decrease this and the frequency with which potentially osteotoxic levels appear in bone grafts have not been studied.

We therefore sought to determine: (1) Does processing of donor bone for allografts result in lower concentrations of lead in commercial allograft when compared with autologous bone graft? (2) What proportion of bone grafts contains levels of lead from $>2.0$ to $20.0 \mu \mathrm{g} / \mathrm{g}$, which would correspond to high levels of donor environmental exposure? In addition, comparison was made of cortical and cancellous bone with regard to concentrations of lead given differences in bone turnover.

\section{Materials and Methods}

Forty-two tibial bone graft specimens consisting of 26 commercially available tibial bone grafts and 16 tibial autograft specimens were obtained. The allograft materials were excess corticocancellous tibial bone graft from surgical procedures in which cortical tibial grafts were used. Autograft specimens tested were fresh-frozen cadaveric tibial cortical and cancellous bone in adult donors with no history of malignancy, tibial fracture, or deformity purchased for the study. Both cortical and cancellous bone graft samples were examined from each specimen in each group for a total of 42 cortical and 42 cancellous specimens. 
Contaminant levels were determined using a PerkinElmer A Analyst 600 atomic absorption spectrophotometer equipped with longitudinal Zeeman background correction and a transverse heated graphite furnace (Perkin Elmer Life and Analytical Sciences, Boston, MA, USA). All instruments, plastic and glassware, were tested for lead contamination by atomic absorption throughout these experiments before every measurement. In addition, the accuracy of the atomic absorption technique was verified using bone meal and standardized calibration with National Institute of Standards and Technology (NIST) materials (Standard Reference Material 1486-Bone Meal; NIST, Gaithersburg, MD, USA).

The lead content of bone from humans exposed to environmental sources ranges from 2 to $20 \mathrm{ppm}$ [20]. In animal models and clinical studies, lead has specifically been shown to be a source of adverse cellular effects resulting in skeletal disease $[3,5,20,22]$. The number of specimens falling within this range was determined for each of the study groups as well as for cortical and cancellous bone specimens. Concentration ranges for groups with $95 \%$ confidence intervals were also calculated. Statistical analysis was performed using SPSS ${ }^{\circledR}$ Statistics 20 $\left(\mathrm{IBM}^{\mathbb{R}}\right.$, Chicago, IL, USA) software for descriptive and comparative statistical analysis [17].

\section{Results}

With the numbers available in the present study, there were no differences in mean lead level between commercial bone graft materials and autogenous bone graft, $2.1 \mu \mathrm{g} / \mathrm{g}$ (95\% confidence interval [CI], $1.6-3.3 \mu \mathrm{g} / \mathrm{g}$ ) versus $2.0 \mu \mathrm{g} /$ $\mathrm{g}(95 \% \mathrm{CI}, 1.0-4.5 \mu \mathrm{g} / \mathrm{g} ; \mathrm{p}=0.86$; Fig. 1). Likewise, there

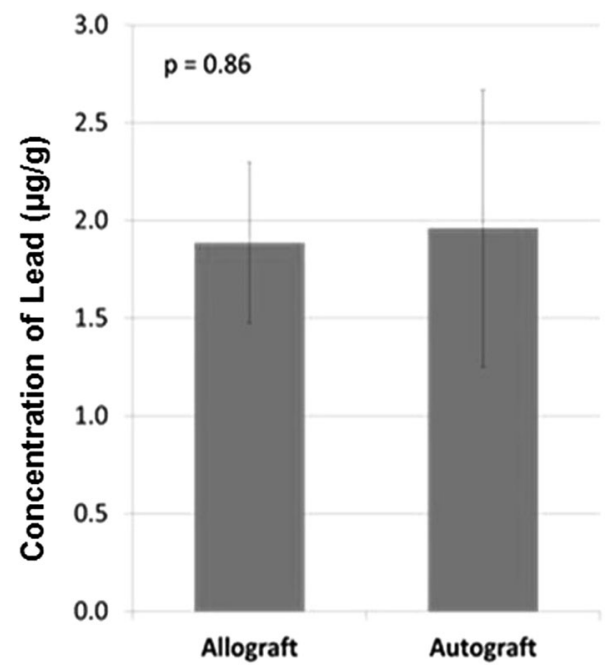

Fig. 1 Lead levels observed in allograft compared with autograft samples are shown with $95 \%$ CIs. were no differences with the numbers available in mean lead level between cortical bone grafts, which contained $2.2 \mu \mathrm{g} / \mathrm{g}(95 \% \mathrm{CI}, 1.5-3.7 \mu \mathrm{g} / \mathrm{g})$, and cancellous grafts, which contained $1.9 \mu \mathrm{g} / \mathrm{g}(95 \% \mathrm{CI}, 1.2-3.4 \mu \mathrm{g} / \mathrm{g} ; \mathrm{p}=0.58$; Fig. 2).

Sixteen of 42 of the specimens $(38 \%)$ had levels between 2 and $5 \mu \mathrm{g} / \mathrm{g}$, within the range expected for individuals with known environmental exposure. The overall lead concentration ranged from the limit of detection at $<0.10 \mu \mathrm{g} / \mathrm{g}$ to $5.0 \mu \mathrm{g} / \mathrm{g}$ (Fig. 3) for a greater than 50 -fold variation.

\section{Discussion}

Lead is a known osteotoxic substance that is preferentially stored in bone for decades and may impact the quality of

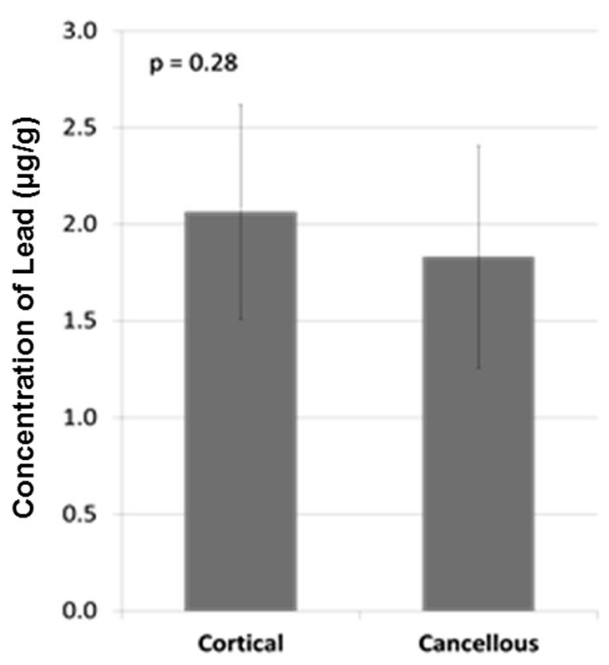

Fig. 2 Leads levels in cortical and cancellous bone are shown with $95 \%$ CIs.

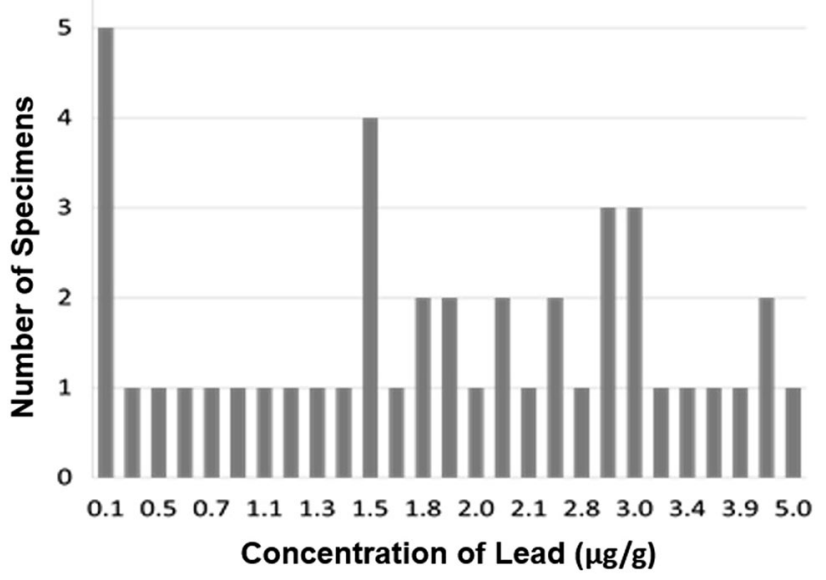

Fig. 3 The distribution of measured lead levels in bone graft materials is shown. 
bone used as graft materials from donors with a history of exposure [2, 4, 14]. Lead has been shown to have deleterious effects on bone formation and cellular remodeling at concentrations as low as 2 parts per million [6, 18, 20]. In children, exposure results in impairment in skeletal development, reduced chest circumference, diminished stature, and can be assessed with blood tests for markers of bone turnover in this population [5, 6, 10-12]. The mechanism and toxicology of lead in bone formation, resorption, and healingis well known being mediated by impairment of the cellular pathways regulating osteoblast and osteoclast function $[3,4,6,8,15,16,18,20,22]$. Presumably the levels of lead in allografts mirror the level of lead in bone in the general population; however, the degree to which processing might decrease this and the frequency with which potentially osteotoxic levels appear in bone grafts have not been studied. We examined if processing of donor bone for allografts resulted in lower concentrations of lead in commercial allograft when compared with autologous bone graft and what proportion of bone grafts contained levels of lead from $>2.0$ to $20.0 \mu \mathrm{g} / \mathrm{g}$ corresponding to donor environmental exposure with potential for associated toxicity. In addition, comparison was made of cortical and cancellous bone with regard to concentrations of lead given differences in bone turnover.

There are limitations to general application of the results of this study alone to all bone graft products. These limitations include the moderate number of specimens from two regional sources, because important geographic differences in lead levels may be present, and so our findings should be corroborated by other studies drawing from additional populations. Lead exposure varies across the country by region and by patient age, which may make any one group of samples nonrepresentative of the population as a whole. An additional study limitation is the relatively limited available history for the individual donors from which bone grafts were acquired outside of published screening protocols for the commercially available allografts $[1,9]$.

Even so the results are consistent with levels from other studied populations with a lack of observed difference between screened bone products and nonscreened bone suggesting that these findings identify an opportunity for further study to improve graft quality [13, 19].

In the present study population, no reduction in lead levels from the processing of donor bone for allografts bone products was observed. There are no additional studies available comparing screened and unscreened bone materials for lead concentration. The specific relationship between a concentration of lead in bone graft materials resulting uniformly to nonunion or failure of fusion is not well defined. Limited data on bone graft supplements and osteotoxicity of lead should not be taken to mean that there are no published data. Population-based studies, animal studies, and cellular studies have found evidence of problematic effects of lead at the levels reported in a proportion of specimens in both screened and unscreened groups of specimens in this study $[5,6,12,18,20]$. Understanding the role of screening for higher concentrations of lead composition incommercially available bone graft materials and potential benefits with regard to reduced nonunion or pseudoarthrosis requires further study.

More than one-third of our specimens had levels greater than $2 \mu \mathrm{g} / \mathrm{g}$, indicating some degree of environmental exposure. Again although it is known that lead in bone can compromise the normal functioning of osteoblasts and osteoclasts, the implications of compositional variation in bone graft materials from donor environmental exposure are not well understood. This study demonstrates that environmental exposure to osteotoxic substances results in contamination levels measurably present in bone graft regardless of the source. Animal studies have suggested that comparable degrees of lead exposure have toxic effects on skeletal tissue and fracture healing [3, 4, 6, 15, 16, 18, 20-23]. In addition, clinical studies are present in the literature demonstrating deleterious effects on bone healing, bone remodeling, and skeletal development [5, 12, 14]. The concentrations of lead reported in $38 \%$ of our specimens have been shown to be osteotoxic in some studies and related to clinical variation in bone health in patients in development and in the setting of fracture healing. Our laboratory has identified deleterious effects on osteoblast and osteoclast function as well as fracture healing at similar concentrations in cellular studies and a murine tibia fracture model [6, 10, 20-22]. This study may identify a unique opportunity to improve the osteoconductive properties of commonly used bone graft materials commonly used in the care of our patients. Additional study of composition of bone graft used in fracture care, fusions, and other procedures is needed.

In conclusion, commercially available bone graft materials tested in this study had a 50-fold variation in the concentration of lead. This variation demonstrates that the idea that each piece of bone or graft is the same is incorrect whether autograft or allograft. One piece of bone may be dramatically different from another in terms of composition when taken from different individuals. In the samples examined in this study, there was no difference between lead levels in autogenous graft and commercial allogeneic bone graft materials, suggesting that in these present study samples, screening for commercial use did result in a measurable change in lead concentrations.

Acknowledgments We thank Robert Gelein $\mathrm{PhD}$, for conducting analytical measurements of lead concentrations in bone specimens for this study. 


\section{Reference}

1. American Association of Tissue Banks. AATB Standards for Tissue Banking. Available at: http://www.aatb.org/StandardsUpdates-for-the-12th-Edition. Accessed October 26, 2015.

2. Auederheide AC, Wittmers LE, Rapp G, Wallgren J. Anthropological applications of skeletal lead analysis. Am Anthropol. 1988;90:931-936.

3. Beier EE, Maher JR, Sheu T-J, Cory-Slechta DA, Berger AJ, Zuscik MJ, Puzas JE. Heavy metal lead exposure, osteoporoticlike phenotype in an animal model, and depression of Wnt signaling. Environ Health Perspect. 2013;121:97-104.

4. Berglund M, Akesson A, Bjellerup P, Vahter M. Metal-bone interactions. Toxicol Lett. 2000;112-113:219-225.

5. Campbell JR, Rosier RN, Novotny L, Puzas JE. The association between environmental lead exposure and bone density in children. Environ Health Perspect. 2004;112:1200-1203.

6. Carmouche JJ, Puzas JE, Zhang X, Tiyapatanaputi P, CorySlechta DA, Gelein R, Zuscik M, Rosier RN, Boyce BF, O'Keefe RJ, Schwarz EM. Lead exposure inhibits fracture healing and is associated with increased chondrogenesis, delay in cartilage mineralization, and a decrease in osteoprogenitor frequency. Environ Health Perspect. 2005;113:749-755.

7. De Long WG, Einhorn TA, Koval K, McKee M, Smith W, Sanders R, Watson T. Bone grafts and bone graft substitutes in orthopaedic trauma surgery. A critical analysis. J Bone Joint Surg Am. 2007;89:649-658.

8. Escribano A, Revilla M, Hernández ER, Seco C, González-Riola J, Villa LF, Rico H. Effect of lead on bone development and bone mass: a morphometric, densitometric, and histomorphometric study in growing rats. Calcif Tissue Int. 1997;60:200-203.

9. Greenwald AS, Boden SD, Goldberg VM, Khan Y, Laurencin CT, Rosier RN, American Academy of Orthopaedic Surgeons. The Committee on Biological Implants. Bone-graft substitutes: facts, fictions, and applications. J Bone Joint Surg Am. 2001;83(Suppl 2):98-103.

10. Hicks DG, O'Keefe RJ, Reynolds KJ, Cory-Slechta DA, Puzas JE, Judkins A, Rosier RN. Effects of lead on growth plate chondrocyte phenotype. Toxicol Appl Pharmacol. 1996;140:164-172.

11. Hoppin JA, Ryan PB, Hu H, Aro AC. Bone lead levels and delinquent behavior. JAMA. 1996;275:1727; author reply 1728 .

12. Kafourou A, Touloumi G, Makropoulos V, Loutradi A, Papanagiotou A, Hatzakis A. Effects of lead on the somatic growth of children. Arch Environ Health. 1997;52:377-383.
13. Lanocha N, Kalisińska E, Kosik-Bogacka D, Budis H, Sokołowski S, Bohatyrewicz A. Comparison of concentrations of lead and cadmium in various parts of the femur head in patients after arthroplasty of the hip joint in northwest Poland. Biomed Environ Sci. 2012;25:577-582.

14. Lanocha N, Kalisinska E, Kosik-Bogacka DI, Budis H, Sokolowski S, Bohatyrewicz A, Lanocha A. The effect of environmental factors on concentration of trace elements in hip joint bones of patients after hip replacement surgery. Ann Agric Environ Med. 2013;20:487-493.

15. Long GJ, Rosen JF, Pounds JG. Lead impairs the production of osteocalcin by rat osteosarcoma (ROS 17/2.8) cells. Toxicol Appl Pharmacol. 1990;106:270-277.

16. Miyahara T, Komiyama H, Miyanishi A, Matsumoto M, Xue-Ya W, Takata M, Takata S, Nagai M, Kozuka H, Yokoyama K. Effects of lead on osteoclast-like cell formation in mouse bone marrow cell cultures. Calcif Tissue Int. 1994;54:165-169.

17. Parsons PJ, Slavin W. A rapid Zeeman graphite furnace atomic absorption spectrometric method for the determination of lead in blood. Spectrochim Acta Part B At Spectrosc. 1993;48:925939.

18. Pounds JG, Long GJ, Rosen JF. Cellular and molecular toxicity of lead in bone. Environ Health Perspect. 1991;91:17-32.

19. Prutsman-Pfeiffer JJ. Lead in the human femoral head: relationships of pathology, environmental exposure, micro-architecture, and biocultural contributions to bone quality.

20. Puzas JE, Sickel MJ, Felter ME. Osteoblasts and chondrocytes are important target cells for the toxic effects of lead. Neurotoxicology. 1992;13:783-788.

21. Zhang X, Schwarz EM, Young DA, Puzas JE, Rosier RN, O'Keefe RJ. Cyclooxygenase-2 regulates mesenchymal cell differentiation into the osteoblast lineage and is critically involved in bone repair. J Clin Invest. 2002;109:1405-1415.

22. Zuscik MJ, Ma L, Buckley T, Puzas JE, Drissi H, Schwarz EM, O'Keefe RJ. Lead induces chondrogenesis and alters transforming growth factor-beta and bone morphogenetic protein signaling in mesenchymal cell populations. Environ Health Perspect. 2007:115:1276-1282.

23. Zuscik MJ, Pateder DB, Puzas JE, Schwarz EM, Rosier RN, O'Keefe RJ. Lead alters parathyroid hormone-related peptide and transforming growth factor-beta1 effects and AP-1 and NFkappaB signaling in chondrocytes. J Orthop Res. 2002;20:811818. 